\title{
Radiation methods \\ in decision support system \\ for food safety
}

Wojciech Migdal,

Urszula Gryczka,

Jerzy Bertrandt,

Tadeusz Nowicki,

Radosław Pytlak

\begin{abstract}
Mathematical model is the basis for computer decision support system (DSS) connected with food security strategy, in which food irradiation is one of the methods used for elimination of substance with pathogens. Such system can support an organisation of many different activities in the area of food safety. It can be designed for a specific region, country, etc., and is addressed to State Sanitary Inspection offices. The paper demonstrates the capabilities of the system in modeling activities of sanitary inspection teams aimed at pathogen elimination with the use of electron beam irradiation in procedures of utilisation of animal originated food, related packaging, or other microbiologically contaminated materials. It describes new application of both computer supported decision systems and radiation processing. The elaborated mathematical models show human activities in the process of microbiological contamination elimination.
\end{abstract}

Key words: decision support system $\bullet$ microbiological food safety $\bullet$ radiation methods

W. Migdal, U. Gryczka ${ }^{\bowtie}$,

Institute of Nuclear Chemistry and Technology,

16 Dorodna Str., 03-195 Warsaw, Poland,

Tel./Fax: +48228638439,

E-mail: u.gryczka@ichtj.waw.pl

\section{J. Bertrandt}

Military Institute of Hygiene \& Epidemiology,

4 Kozielska Str., 01-163 Warsaw, Poland

T. Nowicki

Military University of Technology,

2 Kaliskiego Str., 00-908 Warsaw, Poland

R. Pytlak

Warsaw University of Technology,

8 św. Boboli Str., 02-525 Warsaw, Poland

Received: 26 June 2014

Accepted: 18 September 2014

\section{Introduction}

Different methods for food processing have been developed in order to increase food safety. Nevertheless, WHO reports poisonings and microbiological infections as a remaining global problem. Numerous pathogens and toxins can contaminate food products. Ensuring food safety requires action in a coordinated manner, both at appropriate regulations for the observance of hygiene in the production, processing, transport and distribution of food, efficient system for official controls of food, as well as the implementation of the food production and food processing complying with a law. Natural factors contaminating food, as well as the risk of intentional action in this area (acts of terrorism) are significant threats to public health and the functioning of the state. The computer-based decision system is a tool useful to improve decision-making activities. It is already used for environment and disaster management [1]. Among all instruments available to eliminate the microbiological food contaminants, ionizing radiation seems to be distinctive due to its advantages.

Presented work is a result of project aimed at modeling and simulation of computer supported procedures for food safety and nutrition, in which ionizing radiation is one of method of microbiological contamination elimination. 


\section{Microbiological threats of food products}

In recent years, significant efforts related to food safety were taken, both globally and in individual countries, and the subject became of interest to governments and NGOs. Food borne diseases are an important public health problem in many countries of the world. In the United States, an estimated 9.4 million domestically acquired illnesses and 1351 deaths from known pathogens are reported each year [2]. In the U.S., infections transmitted by food that are tracked by the Food Borne Diseases Active Surveillance Network (FoodNet). A total of 19531 infections, 4563 hospitalizations, and 68 deaths associated with food borne diseases were reported in 2012. For most infections, incidence was highest among children aged $<5$ years; the percentage of people hospitalised and the percentage who died were highest among people aged $\geq 65$ years. In 2012, compared with the 2006-2008 period, the overall incidence of infections was unchanged, and the estimated incidence of infections caused by Campylobacter and Vibrio increased. These findings highlight the need for targeted actions to address food safety gaps [3]. The six key pathogens causing more than $50 \%$ of food borne illnesses are: Campylobacter, Listeria, Salmonella, STEC O157, Vibrio, and Yersinia [4]. In Poland, the number of infectious diseases of the gastrointestinal tract amounted in 2012 to 10478 cases, of which 8444 cases were related to Salmonella [5].

In light of the events showing the toughness and strength of global terrorism, particularly important becomes the issue of protecting food against the possibilities of using it in terrorist activities, mainly as a transmitter of biological weapons. Food terrorism is defined as: an act, or threat of deliberate contamination of food for human consumption with biological, chemical, physical agents, or radionuclear materials for the purpose of causing injury, or death to civilian populations and/or disrupting social, economic, or political stability. The biological agents referred to are infectious, or non-infectious pathogenic microorganisms, including viruses, bacteria and parasites [6]. U.S. Centers for Disease Control and Prevention (CDC) has classified the importance of biological agents of bioterrorism. Among the most dangerous microorganisms that cause food borne diseases (group A) are rod anthrax (Bacillus anthracis) and Clostridium botulinum (C. botulinum). Most biological agents are classified to group B. These pathogens cause gastrointestinal disorders, however, the morbidity and mortality resulting from these disorders is lower in comparison with the factors of group A. This group includes microorganisms of the genus Salmonella, Shigella dysenteriae, Escherichia coli O157:H7, Vibrio cholerae and Staphylococcal enterotoxin B, and ricin - a biological toxin extracted from the castor bean seeds (Ricinus communis) [7].

Food bioterrorism can result from:

- the direct impact of contaminated food on the human food chain, where the cells act as a transmitter of biological agent;
- indirect action, by carrying out a biological attack on agriculture and agri-food industry.

The terrorist attack on food can be done anywhere in human food chain from field to table. There are documented examples proving that terrorists could use food as a transmitter of biological agents to achieve their goals. In 1984, the religious sect 'Rajneesh' infected the salad in salad bars at famous restaurants in the Dallas, Oregon. 751 confirmed cases of infection with chopsticks Salmonella typhimurium were reported. The aim of the operation was to prevent local elections [8]. In connection with the real threat of the use of food as a transmitter of biological weapon, food safety is of great importance throughout the process of its manufacture, processing, storage and distribution.

\section{The use of ionizing radiation for microbiological decontamination}

The food products can be irradiated using gamma rays, $\mathrm{x}$-rays or high energy electrons. Development in the field of radiation sources, especially in electron accelerators and $\mathrm{e}^{-} / \mathrm{X}$ systems, opens new areas of application in elimination of microbial hazards [9]. The advantages of ionizing radiation application in disinfection, or sterilisation process compared to chemical or thermal methods are: short time of the process; absence of chemical agents; avoiding high temperatures; controlled penetration. On the other hand, the disadvantage of e-beam technology is limited range of electron in irradiated product. Depending on equipment parameters it can be used for surface, or entire object irradiation. The comparison of penetrating ability and costs of different sanitising technologies was discussed by Henry [10].

Food irradiation process is a technology approved by FAO/WHO to reduce food loses, by extending shelf-life, by inhibiting sprouting and to increase the safety of food by elimination of pests and microbiological pathogens. Ionizing radiation is also widely used for medical devices sterilisation.

In a crisis situation, ionizing radiation has already been used for mail sanitation in October 2001 in USA, after terrorist attacks with the use of anthrax spores. The Bridgeport Electron Beam and X-ray facility has been modified and now is used to protect the White House, Congress and various federal agencies [10-12]. In 2004 the possibilities of ionizing radiation application in inactivation of bioterrorism agents was discussed at NATO Advanced Research Workshop in Budapest, Hungary. The recommendations of the workshop were:

- to assess the potential use of ionizing radiation for the destruction biologically hazardous materials,

- to develop and maintain a database on the use of radiation technologies for biological agent defeat,

- to compile a list of radiation sources and locations capable of contributing to biological agent inactivation [13].

WHO "Food borne disease outbreaks: Guidelines for investigation and control" recommends irradia- 
Table 1. Values of $D_{10}$ dose for selected microorganisms

\begin{tabular}{lcc}
\hline \multicolumn{1}{c}{ Microorganism } & $\mathrm{D}_{10}$ dose & Reference \\
\hline Escherichia coli O157: $\mathrm{H} 7$ & 0.30 & {$[11]$} \\
Staphylococcus aureus & 0.46 & {$[11]$} \\
Salmonella spp. & 0.70 & {$[11]$} \\
Clostridium botulinum & 3.56 & {$[11]$} \\
Bacillus anthracis spores & 3.53 & {$[16]$} \\
\hline
\end{tabular}

tion as one of the methods of control and prevention of major food borne diseases like: Escherichia coli infection, salmonellosis, cholera, etc. [14]. Also in case of Anthrax contamination the WHO "Guidelines for the Surveillance and Control of Anthrax in Human and Animals", recommends: in countries where irradiation facilities are available, the preferred approach is to sterilise the materials of animal origin by irradiation [15].

The radiation method is highly effective against a number of pathogenic microorganisms. Effectiveness of the process depends on applied doses. For the most common food pathogens, their radiation sensitivity can be found in literature. The pathogens resistance to irradiation expressed as a dose $D_{10}-$ dose needed for the 10-fold reduction of microorganism population for selected organisms is presented in Table 1.

\section{Computer decision support system}

The development of a computer based information system has started in the 70s of the 20th century. The system designed to collect data and to support decision-making activities is called decision support system (DSS). The key elements of each DSS according to Demares 2005 [17] are:

- individual, or a group of people defined as a decision maker,

- the input data including models of interpreting data,

- decision making process itself,

- outputs.

The growing interest in information based technologies gives opportunity to improve the procedures of action in the face of food borne diseases. The system includes the database of population, regions, selected food borne diseases as well as norms and procedures for control, prevention and elimination of diseases. The created DSS for the needs of food safety and nutrition management is addressed to sanitary inspection, which is the decision-making body responsible for monitoring, preventing, or elimination of disease outbreaks. The investigation and reporting of food borne outbreaks within European Union become mandatory under decision of European Parliament (2119/98/EC, 1786/2002/EC, 2003/99/EC). The regulations include the guideline for monitoring and reporting of disease cases, creating international network for food borne outbreaks, analysis of disease data, action of elimination and prevention of the contamination. The action of sanitary inspection in case of food borne diseases must include the elimination of contamination and prevention of further development of disease, i.e.:

- current disinfection - it is often preventive action in premises connected with the distribution of food and water,

- final disinfection - typically performed after completing examination of the facility,

- physical disposal - this applies to animal and plant food, which contains pathogen,

- chemical disposal - this applies to the contaminated water.

Ionizing radiation is a physical method of antiepidemic action to eliminate the microbiological burden. Realisation of the irradiation process needs the input data, which include information about the type and level of microbial contamination as well as characteristic of contaminated object (dimension, material type and its density etc.). The doses applied in the process must be selected by taking into account: type and initial concentration of microorganisms, expected effect of irradiation as well as geometry and density of irradiated substance. As the microorganisms have different sensitivity to ionizing radiation the database of microorganisms $\mathrm{D}_{10}$ must be created.

\section{Modeling of the microbiological contamination elimination process}

The decision support system (DSS) for food safety includes the database of population, regions, description of selected food borne diseases as well as norms and procedures for control, prevention and elimination of diseases. One of the elements of the DSS is modeling component, which enables the description of the utilisation processes. The discussion in this paper process is aimed at planning activities of sanitary inspection teams related to the elimination of contaminants in sterilisation processes by physical or chemical method.

For the description of these processes, two approaches are used: the first one describes the processes as events driven and shows human activities as a workflow, the second one uses a dynamical model in the form of differential-algebraic equations.

\section{Business model}

The process of determining the quantities of substances with potential pathogen is strongly associated with sanitary inspectors conducted interviews with patients being the result of an epidemic. These interviews lead to the list of potential places of epidemic outbreaks and to epidemic spread roads. It is clear that source of the epidemic (warehouses, commercial buildings, water supply, etc.), are the places where the pathogen is located. After determining the list of potential sources and ways of spreading epidemics, the objects placed on the list should be controlled by sanitary inspectors. Swabs are collected in the objects and transferred for further research. After we detect the substance with the pathogen, we call the object source of the epidemic. 
In the case when many locations of outbreak are found, the sanitary inspectors have to check the amount of contaminated substance and the amount of substance that has been sent to other objects or individual customers. Action against epidemic shall be continued until the expiry of the epidemic. At the end of epidemic, numerous messages and reports should be sent by sanitary inspectors. It is worth to say that the process of utilisation of the substance with pathogen is often overlooked in the various deliberations on anti-epidemic activities.
It should be noted that during inspection substantial amount of material with a pathogen is taken from a site. Any decision related to the use of substances with the pathogen is taken by the state sanitary inspector.

The substance with the pathogen must be disinfected or eliminated. In this case, the radiation method can be used. Activities associated with the use of radiation method for disinfection are shown in detail in the diagram (Fig. 1). This diagram was prepared in the software environment ARIS (Software AG) [18,

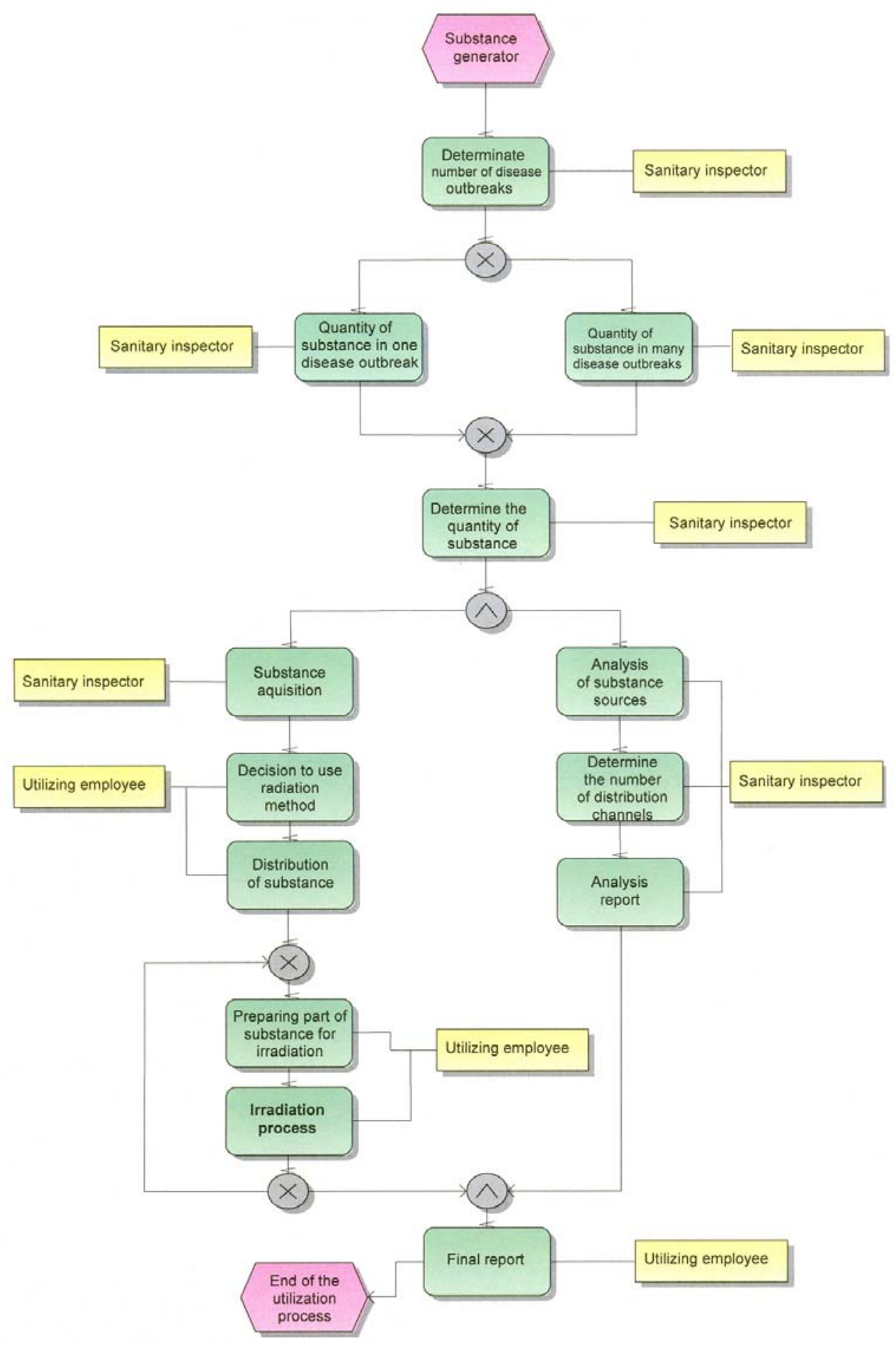

Fig. 1. Business process diagram in ARIS environment for planning activity connected with use of radiation method for disinfection of microbiologically contaminated products. 
19], in which it is possible to simulate the disinfection process of substance with radiation method.

\section{Systems Dynamics model}

The modeling component of DSS uses the Forrester's methodology for building dynamical models of complex systems [20]. The methodology was proposed by Forrester in late 50s of the previous century and initially was applied to describe dynamical behaviour of activities of any organisation, in particular industrial company. Later the methodology was successfully applied to any kind of human activities including decision making processes. According to the Forrester's methodology, the model of a process is built in two stages. In the first stage main variables of the process are listed and the relations between them are stated. In that stage, so-called casual loop diagram (CLD) is constructed, which reveals closed loops in the process, which can be analysed and used for the verification of the correctness of the process model. For example, if the process has variables, which historical values show exponential growth, there must be at least one positive closed loop in the CLD of the process.

In the second stage, the CLD of the process is transformed into a set of differential-algebraic equations. It is done by stating that some variables in the CLD must be differential variables, which means that there must be differential equations associated with these variables, the other variables of the CLD define algebraic equations. In the second stage to each variable (differential or algebraic) some function (in general nonlinear) is assigned. At the end of the modeling process, we have a set of differential-algebraic equations.

Figure 2 presents the model (developed with the help of Vensim software [21]) concerning the elimination of pathogen using radiation methods. In the model it was assumed that:

- there are reported cases of contaminated food;

- sanitary inspection teams are created to analyse the cases;

- some reported cases are not confirmed;

- elimination of the pathogen is restricted by available funds;

- if funds are not available then pathogen elimination activity is discarded.

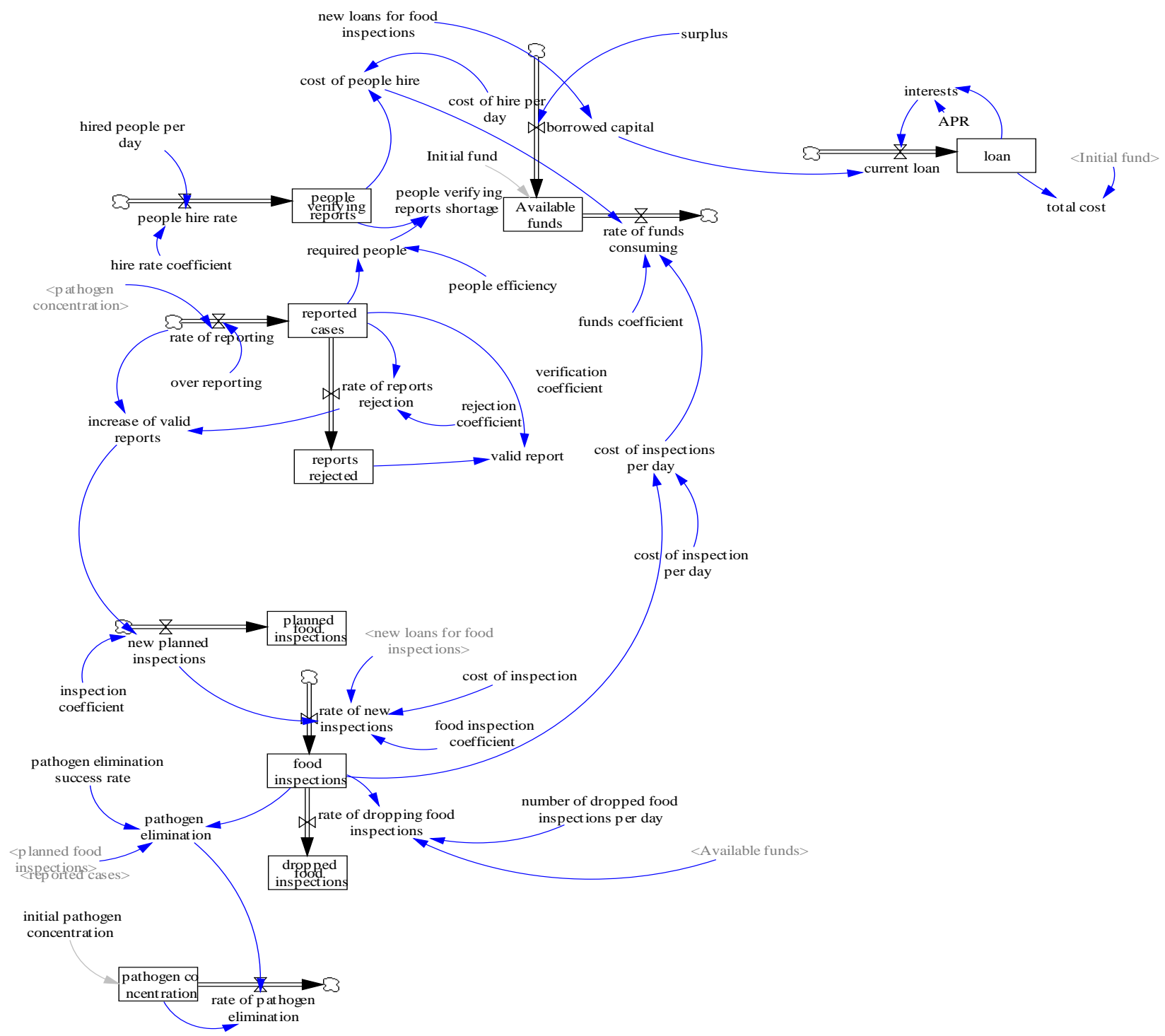

Fig. 2. Systems Dynamics model of the radiation utilisation process. 


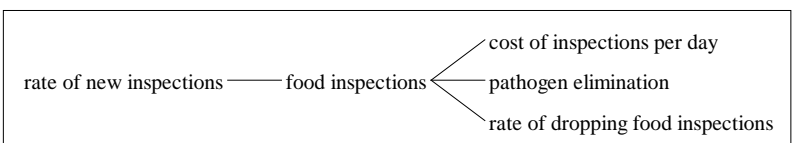

Fig. 3. Dependence tree for the variable 'rate of new inspection'.

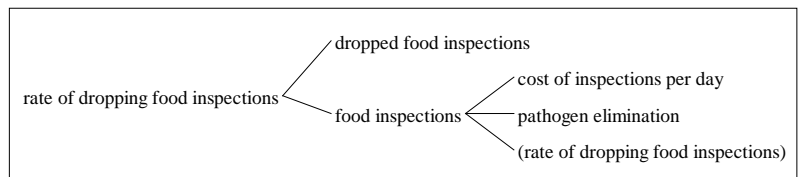

Fig. 4. Dependence tree for the variable 'rate of dropping food inspection'.

The model has 52 differential-algebraic equations, among which there are nine differential equations. The model has several decision rules. One of them is associated with the variable rate of new inspection. Its dependence tree is given in Fig. 3 .

The decision rule concerning this variable has the following expression:

rate of new inspections $=$ food inspection coefficient*(IF THEN ELSE (INTEGER
(MAX (new loans for food inspections/cost of inspection,0)) >new planned inspections, new planned inspections, INTEGER (MAX (new loans for food inspections/cost of inspection,0)))).

The decision rule states that if new loans for food inspections are sufficient for funding new planned inspections, then these inspections are created. Furthermore, the number of new inspections depends on available funds.

The other decision rule appears in the definition of the variable rate of dropping food inspections with the following dependence tree (Fig. 4). The decision rule concerning this variable has the following expression:

rate of dropping food inspections $=$ IF THEN ELSE ( ( Available funds <0):AND: (number of dropped food inspections per day>0)), MIN((number of dropped food inspections per day), (food inspections) $), 0)$.

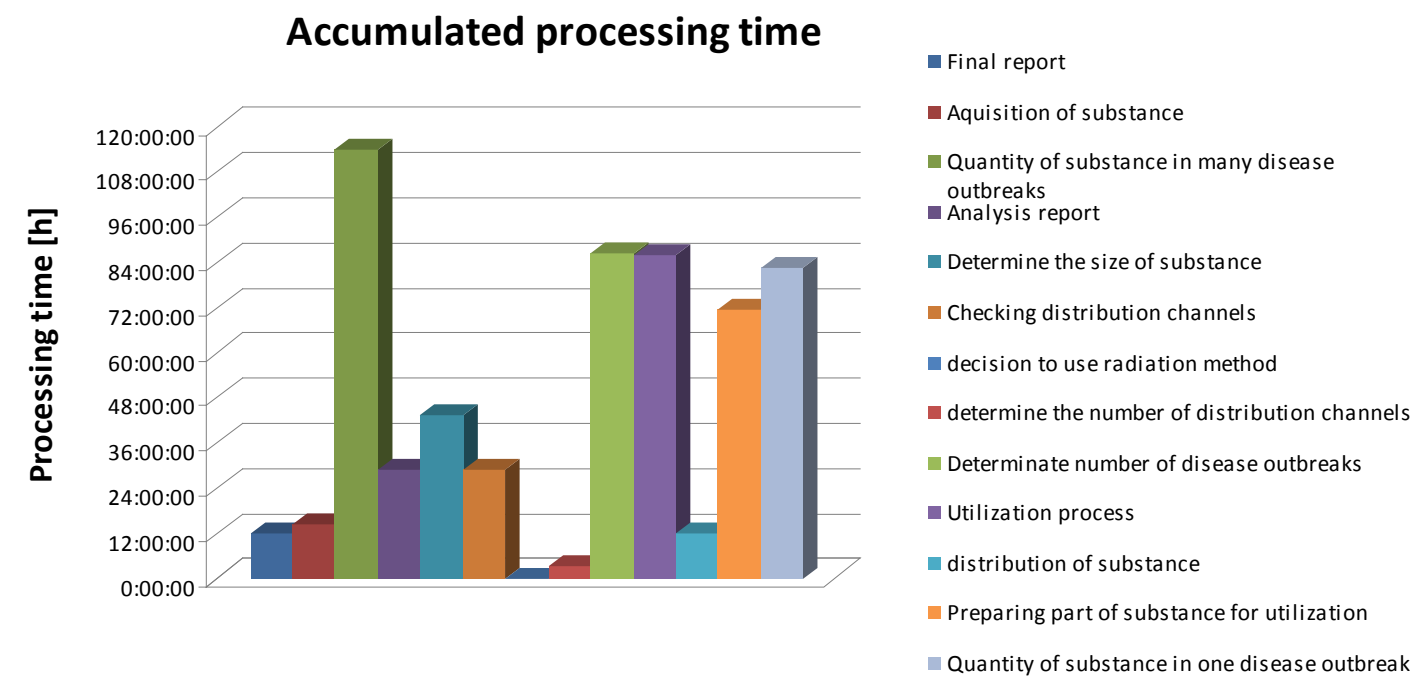

Fig. 5. Total sum of processing times of the various significant activities during the substance elimination process.

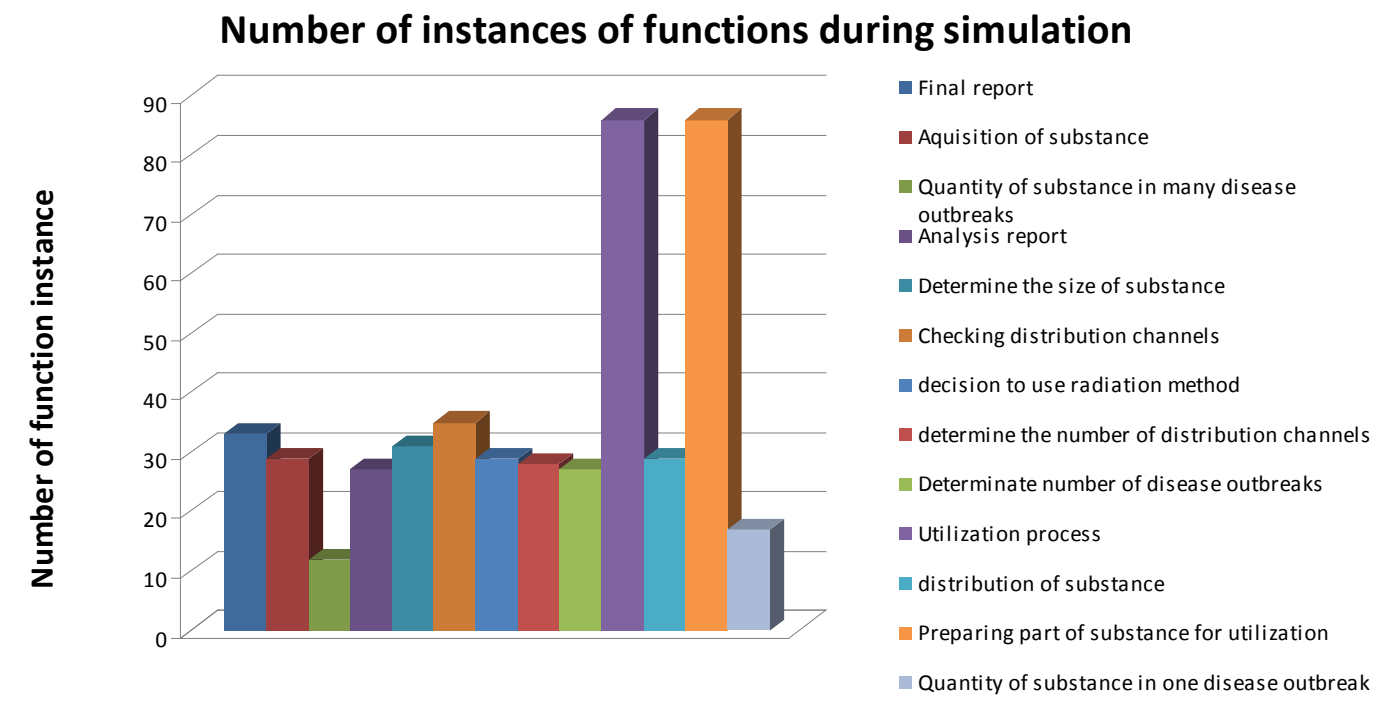

Fig. 6. Number of instances of functions during simulation. 


\section{Simulations of the models}

As a result of simulation experiments, the following characteristics related to the utilisation process were obtained:

- the total sum of processing times of various activities carried out during the substance elimination process (Fig. 5).

- number of instances of functions during simulation (Fig. 6).

- total time of different tasks execution obtained during the process of substance elimination process (Fig. 7).

- load level of employees work obtained during the substance elimination process (Fig. 8).

It is worth to notice that it is not possible to obtain such characteristics in the static analysis of a business process.

The Systems Dynamics model has been implemented and simulated. The trajectories of the main model variables are presented in Fig. 9. These trajectories show the effectiveness of the proposed decision making process - the increased number of reported cases of infected people intensifies the activities of sanitary inspection teams leading to the pathogen elimination.

\section{Conclusions}

The DSS have already been designed for the simulation and control of the processes related to broadly treated environment. The paper presents elements of the DSS dedicated to decision making processes of sanitary inspection teams during outbreaks of food borne diseases. The discussed DSS is equipped with modeling and simulation tools, which enables, in

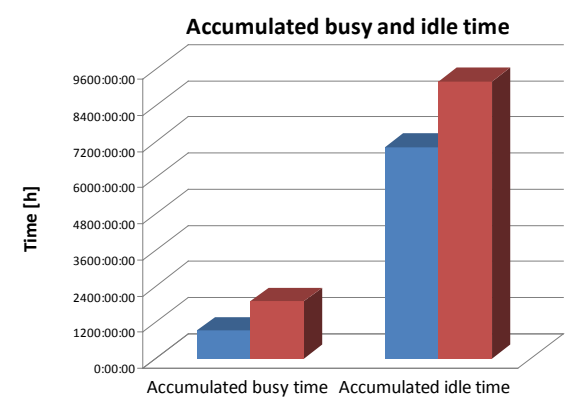

nutilizing employee

In sanitary inspector

Fig. 7. Accumulated time corresponding to person activities during the substance elimination process.

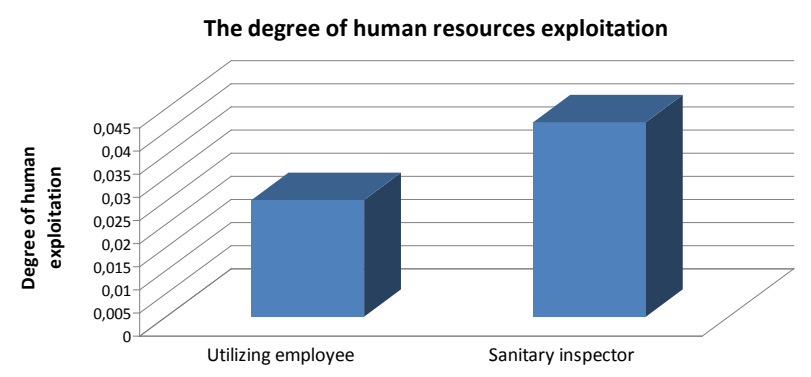

Fig. 8. Degree of different people activity during the substance elimination process. particular, analysing processes related to pathogen elimination by using radiation methods.

The aim of performed simulation was to demonstrate the capabilities of the system. The system offers two types of modeling tools. The first one employs ARIS environment for making eEPC diagrams, which through simulation can reveal bottlenecks of sanitary inspection teams' activities. The second one uses Systems Dynamics methodology, which allows treating sanitary inspection teams' activities as truly

A. Graph for the number of reported cases

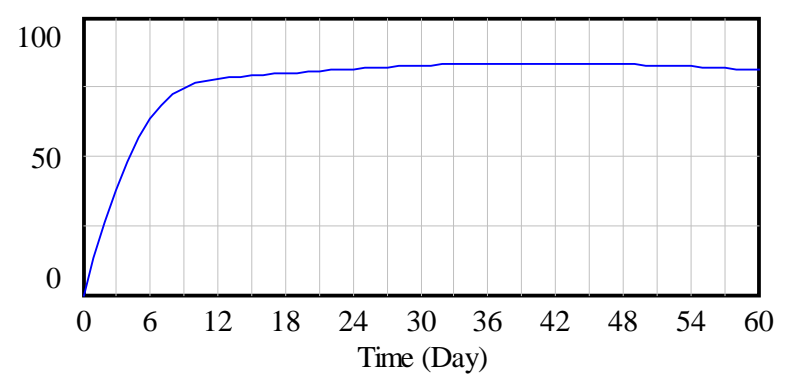

reported cases : Current number

B. Graph for the number of food inspections

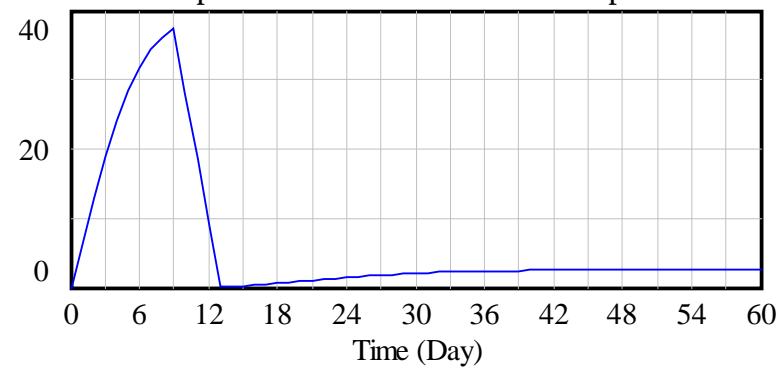

food inspections : Current number

C. Graph for the rate of pathogen elimination

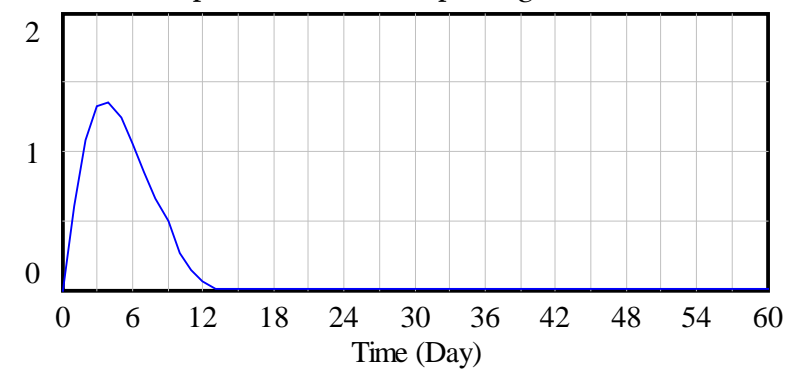

rate of pathogen elimination : Current - mln bacteria/(Day*g)

D. Graph for the pathogen concentration

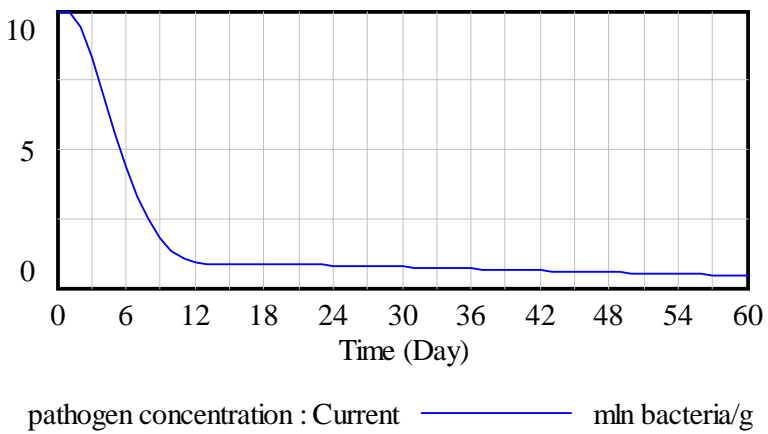

Fig. 9. The trajectories of the main dynamic model variables. 
dynamic processes. The models obtained with the help of this methodology enables analysing decision making processes associated with these activities (by taking into account also closed loops present in these processes). Both discussed approaches can be very useful for efficient realisation of sanitary inspection teams' activities.

\section{References}

1. Cioca, M., \& Cioca, L. (2010). Decision support systems used in disaster management. Chiang S. Jao (Ed.), Decision support systems. InTech, from InTech Open Science, http://www.intechopen.com/books/ decision-support-systems/decision-support-systemsused-in-disaster-management. DOI: 10.5772/39452.

2. Scalan, E., Hoekstra, R. M., Angulo F. J., Tauxe, R. V., Widdowson, M. A., Roy, S. L., Jones, J. L., \& Griffin, P. M. (2011). Foodborne illness acquired in the United States - major pathogens. Emerg. Infect. Dis., 17, 7-15. DOI: 10.3201/eid1701.091101p1.

3. Centers for Disease Control and Prevention. (2013). Incidence and trends of infection with pathogens transmitted commonly through food, 1996-2012. Foodborne Diseases Active Surveillance Network. 10 U.S. Sites. CDC Weekly Report, April 19, 62(15), 283-287.

4. Henao, O. L., Crim, S. M., \& Hoekstra, R. M. (2012). Calculating a measure of overall change in the incidence of selected laboratory-confirmed infections with pathogens transmitted commonly through food. Foodborne Diseases Active Surveillance Network (FoodNet). Clin. Infect. Dis., 54(Suppl. 5), 418-420.

5. National Institute of Public Health, National Institute of Hygiene, Department of Epidemiology. (2013). Infectious diseases and poisonings in Poland in 2012. Warsaw.

6. World Health Organization, Food Safety Department (2002). Terrorist threats to food: guidance for establishing and strengthening prevention and response systems. Geneva: WHO Press.

7. U.S. Food and Drug Administration, CFSAN/Office of Regulations and Policy. (2003). Risk assessment for food terrorism and other food safety concerns. Washington. Federal Register (Vol. 68, Issue 197).

8. Torok, T. J., Tauxe, R. V., \& Wise, R. P. (1987). A large community outbreak of Salmonella caused by intentional contamination of restaurant salad bars. J. Am. Med. Inf. Assoc., 278, 389-395.

9. Chmielewski, A. G., \& Haji-Saeid, M. (2004) Radiation technologies: past, present and future. Radiat. Phys. Chem., 71, 17-21. DOI: 10.1016/j.radphyschem.2004.05.040.

10. Henry, T. G. (2005). Inactivation of bio-terrorism agents in military and domestic application. In L. G. Gazso \& C. C. Ponta (Eds.), Radiation inactivation of bioterrorism agents (pp. 147-152). Amsterdam: IOS Press.

11. Desrosiers, M. F., Coursey, B., Seltzer, S., Hudson, L., Puhl, J., Bergstrom, P., Bateman, F., Cooper, S., Alderson, D., Knudson, G., Elliott, T., Shoemaker, M., Lowy, J., Miller, S., \& Dunlop, J. (2005). Irradiation decontamination. In L. G. Gazso \& C. C. Ponta (Eds.), Radiation inactivation of bioterrorism agents (pp. 115-126). Amsterdam: IOS Press.

12. Desrosiers, M. F. (2004). Irradiation applications for homeland security. Radiat. Phys. Chem., 71, 479-482. DOI: 10.1016/j.radphyschem.2004.03.084.

13. Lowy, R. J., Elliott, T. B., Shoemaker, M. O., Knudson, G. B., \& Desrosiers, M. F. (2005). Foreword. In L. G. Gazso \& C. C. Ponta (Eds.), Radiation inactivation of bioterrorism agents (pp. V-VII). Amsterdam: IOS Press.

14. World Health Organization. (2008). Foodborne disease outbreaks: Guidelines for investigation and control. Geneva: WHO Press.

15. Turnbull, P. C. B., \& Böhm, R. (1993). Guidelines for the surveillance and control of anthrax in humans and animals. WHO. (WHO/EMC/ZDI/98.6).

16. Niebuhr, S. E., \& Dickson, J. S. (2003). Destruction of Bacillus anthracis strain Sterne 34F2 spores in postal envelopes by exposure to electron beam irradiation. Lett. Appl. Microbiol., 37, 17-20. DOI: 10.1046/j.1472-765X.2003.01337.x.

17. Demarest, M. (2005). Technology and policy in decision support systems. DSSResources.COM. http:// dssresources.com/papers/features/demarest05/ demarest07082005.html.

18. Scheer, A. W. ASIM Dynamic simulation with ARIS IDS Scheer AG, 2003/2004.

19. Brabander, E., \& Davis, R. (2007). ARIS Design platform. Getting started with BPM. London: Springer.

20. Sterman, J. D. (2000). Business dynamics. System thinking and modeling for complex world. Kingsport: McGraw-Hill Higher Education.

21. Vensim Ventana Systems. (2014). Vensim user's guide, from http://vensim.com/docs. 